SCIENTIFIC LETTER

\title{
Reduction in plasma concentrations of $N$ terminal pro $B$ type natriuretic peptide following percutaneous coronary intervention
}

\author{
P R Kalra, A Gomma, C Daly, J R Clague, I B Squire, L L Ng, K F Fox
}

Heart 2004;90:1334-1335. doi: 10.1136/hrt.2003.018051

B type natriuretic peptide (BNP) and its pro-peptide $\mathrm{N}$ terminal fragment (NTproBNP) are raised in conditions associated with abnormal ventricular structure and function and are independent predictors of survival in diverse clinical settings. Patients without raised baseline plasma BNP demonstrate an early, transient increase in concentrations following percutaneous coronary intervention (PCI), ${ }^{1}$ but longer term effects are unknown. Potential benefits of PCI on ventricular remodelling are likely to be greatest in patients with raised baseline plasma BNP concentrations, reflecting increased wall stress or ongoing ischaemia. We hypothesised that in patients with stable coronary disease and an elevated baseline NTproBNP, successful PCI would result in a significant reduction in the plasma concentration.

\section{METHODS}

The study population was recruited from a larger prospective study of risk factors for coronary in-stent restenosis. ${ }^{2}$ To define an elevated baseline value, NTproBNP was measured in a group of 30 healthy volunteers of similar age and sex distribution (mean age 50 years, $83 \%$ male) to the patient group who had no history or clinical signs of cardiovascular disease, and underwent comprehensive non-invasive testing to exclude cardiac pathology. The 90th centile was selected as the cut-off value to define raised NTproBNP, corresponding to an NT proBNP concentration of $>75 \mathrm{fmol} / \mathrm{ml}$. Local ethics committee approval was obtained and all subjects gave written informed consent.

Twenty eight patients with stable angina and raised baseline NTproBNP, undergoing elective, single native vessel stenting to de novo lesions, were included in the PCI group. Blood was drawn before intervention, and then 1, 6, and 24 hours after the procedure. A final sample was obtained at six months follow up. The control group consisted of 13 patients with stable angina and elevated baseline plasma NTproBNP who underwent coronary angiography without subsequent PCI. In these patients bloods were drawn at baseline, 1, 6, and 24 hours, and 7 days post-angiography. Data were also available on a further 19 patients undergoing elective stenting in whom baseline NTproBNP was not raised (that is $\leqslant 75 \mathrm{fmol} / \mathrm{ml}$ ).

NTproBNP was analysed by immunoluminometric assay. NTproBNP concentrations are presented as median and interquartile ranges, and were log transformed for analysis.

\section{RESULTS}

Clinical characteristics were similar in the PCI and control groups (table 1). Ventricular function at baseline was assessed in 32 of the 41 patients and clinical heart failure was an exclusion criterion for the main study; 17/32 had normal function, 12/32 had moderate dysfunction, and 3/32 had severe dysfunction. NTproBNP concentrations did not vary according to category of left ventricular function.
Table 1 Characteristics of patients with ischaemic heart disease undergoing elective $\mathrm{PCl}$ ( $\mathrm{PCl}$ group) or angiography without intervention (control group). The $p$ value relates to differences between the two groups

\begin{tabular}{|c|c|c|c|}
\hline & $\begin{array}{l}\mathrm{PCl} \text { group } \\
(\mathrm{n}=28)\end{array}$ & $\begin{array}{l}\text { Control group } \\
(n=13)\end{array}$ & $p$ Value \\
\hline Age (years) & $60(2)$ & $62(2)$ & 0.4 \\
\hline Males (\%) & $21(75)$ & 10 (77) & 0.9 \\
\hline CRP $(\mathrm{mg} / \mathrm{ml})$ & $3.5(0.5)$ & $3.9(0.7)$ & 0.7 \\
\hline Creatinine $(\mu \mathrm{mol} / \mathrm{l})$ & $95(5)$ & $89(5)$ & 0.5 \\
\hline MI (\%) & 11 (39) & $8(62)$ & 0.2 \\
\hline Hypertension (\%) & $12(43)$ & $3(23)$ & 0.2 \\
\hline \multicolumn{4}{|l|}{ Medication } \\
\hline$\beta$ Blockers (\%) & $22(79)$ & $7(54)$ & 0.1 \\
\hline ACEi/AllRB (\%) & $12(43)$ & $5(38)$ & 0.8 \\
\hline Diuretics (\%) & $6(21)$ & 5 (38) & 0.3 \\
\hline
\end{tabular}

Data are expressed as mean (SEM) or as proportions.

ACEi, angiotensin converting enzyme inhibitors; AllRB, angiotensin II receptor blocker; CRP, C reactive protein; $\mathrm{Ml}$, myocardial infarction; NTproBNP, N terminal B type natriuretic peptide; $\mathrm{PCl}$, percutaneous coronary intervention.

Baseline NTproBNP concentration was 257 (170771) $\mathrm{fmol} / \mathrm{ml}$ in the PCI group and 188 (106-550) fmol/l in the control group $(p=0.5)$. In the PCI group plasma NTproBNP concentrations decreased over time (analysis of variance (ANOVA) $\mathrm{p}<0.0001)$. Concentrations at 1 hour (281 (192-721) fmol/ml) and 6 hours (246 (137-688) fmol/ $\mathrm{ml}$ ) were similar to baseline (both $\mathrm{p}>0.1$ ), but a significant reduction was seen by 24 hours (207 (53-588) fmol/ml, $\mathrm{p}=0.006 v$ baseline). A further reduction in NTproBNP was seen at 6 months $(145(66-369) \mathrm{fmol} / \mathrm{ml}, \mathrm{p}=0.0003 v$ baseline).

In the control group NTproBNP concentrations increased between 1 and 6 hours following angiography (232 (138551) v 271 (177-726) fmol $/ \mathrm{ml}$, respectively, $\mathrm{p}=0.036)$. In contrast, baseline concentrations were similar to those at 24 hours (188 (106-550) v 197 (115-344) fmol/ml, respectively, $\mathrm{p}=0.24)$. Data were not available for three of the patients at day 7. In the remaining 10 patients NTproBNP concentrations did not change significantly between baseline and 7 days $(210(109-547) v 300(140-596) \mathrm{fmol} / \mathrm{ml}, \mathrm{p}=0.15)$. In the patients whose baseline NTproBNP was not raised ( 14 (14-26) fmol/ml), plasma concentrations did not change over time (ANOVA $p=0.22$ ). These results were not materially altered by sensitivity analysis using the 75 th or 95 th centiles as the threshold for high NTproBNP.

Abbreviations: $\mathrm{BNP}, \mathrm{B}$ type natriuretic peptide; $\mathrm{PCl}$, percutaneous coronary intervention; NTproBNP, N terminal pro B type natriuretic peptide 


\section{DISCUSSION}

Previous studies with patients without raised BNP concentrations at baseline have shown a transient increase in BNP following PCI, thought to be related to myocardial ischaemia during balloon inflation. ${ }^{1}$ In contrast, we have found that in patients with raised NTproBNP at baseline, PCI was associated with a decrease in concentrations within 24 hours. This reduction is maintained, or even augmented, at six months.

The degree to which the reduction in NTproBNP is determined by improved left ventricular function and geometry, or by a reduction in ischaemic burden, remains to be established. Plasma NTproBNP concentrations are strongly related to left ventricular function in patients with recent myocardial infarction, ${ }^{3}$ but it has also been demonstrated that NTproBNP is elevated in patients with stable angina, even with preserved ventricular function, compared to healthy controls, suggesting that chronic or recurrent acute ischaemia may contribute to raised concentrations of NT proBNP. ${ }^{4}$ The absence of consistent sequential assessment of ventricular function is a limitation of this study.

While PCI is an effective means of alleviating symptoms in stable coronary disease, data supporting consistent mortality benefits are lacking. The finding that PCI can reduce raised plasma NTproBNP concentration may have important clinical implications. Raised plasma BNP and NTproBNP predict adverse prognosis in a number of clinical states, and it has been suggested that the assessment of BNP may identify high risk patients with acute coronary syndromes who could benefit from early aggressive intervention. ${ }^{5}$ In heart failure, treatment titrated to reduce plasma NTproBNP improves clinical outcome compared to standard clinical practice. ${ }^{6}$ We have demonstrated a significant and sustained reduction in NTproBNP in patients undergoing PCI who had raised concentrations before the intervention. Given the wealth of evidence supporting NTproBNP as a prognostic indicator, and emerging evidence that measures which reduce NTproBNP are associated with improved clinical outcome, it is tempting to speculate that a reduction in plasma NTproBNP concentrations towards the normal range following revascularisation might indicate a prognostic benefit.
This study shows that raised NTproBNP concentrations in patients with stable angina may be reduced by PCI. It was not designed to elucidate the prognostic importance of the reduction, or the pathophysiological mechanisms behind it. The findings are both exciting and challenging, with further evaluation required to determine whether this primarily relates to a reduction in ischaemic burden or changes in left ventricular function, although these are tightly interrelated. The effect on outcome of the reduction of NTproBNP and the potential to use it to target the use of PCI needs to be addressed in larger prospectively collected populations.

\section{Authors' affiliations}

P R Kalra*, A Gomma*, C Daly, J R Clague, K F Fox, Royal Brompton Hospital and National Heart and Lung Institute, Imperial College School of Medicine, London, UK

I B Squire, L L Ng, Department of Medicine and Therapeutics, University of Leicester, Leicester, UK

*These authors contributed equally to this work

Correspondence to: Dr Caroline Daly, Cardiology Fellow, Royal Brompton Hospital, Sydney Street, London, SW3 6LY, UK; c.daly@rbh. nthames.nhs.uk

Accepted 23 January 2004

\section{REFERENCES}

1 Kyriakides ZS, Markianos M, Michalis L, et al. Brain natriuretic peptide increases acutely and much more prominently than atrial natriuretic peptide increases acutely and much more prominently than atrial natric
during coronary angioplasty. Clin Cardiol 2000;23:285-8.

2 Gomma AH, Elrayess MA, Knight CJ, et al. The endothelial nitric oxide synthase (Glu298Asp and -786T >C) gene polymorphisms are associated with coronary in-stent restenosis. Eur Heart J 2002 23:1955-62.

3 Daly $C$, Henein $M$, Wright $C$, et al. The neurohumoral response to exercise in coronary heart disease and the relationship with inducible ischaemia. J Am Col Cardiol 2003;41(6 suppl A):359.

4 Talwar S, Squire IB, Downie PF, et al. Profile of plasma N-terminal proBNP following acute myocardial infarction; correlation with left ventricular systolic dysfunction. Eur Heart J 2000;21:1514-21.

5 de Lemos JA, Morrow DA, Bentley JH, et al. The prognostic value of B-type natriuretic peptide in patients with acute coronary syndromes. N Engl J Med 2001;345:1014-21.

6 Troughton RW, Frampton CM, Yandle TG, et al. Treatment of heart failure guided by plasma aminoterminal brain natriuretic peptide (NT-BNP) concentrations. Lancet 2000;355: 1126-30. 